\title{
A guide to publishing scientific research in the health sciences
}

\author{
P Huston ${ }^{1,2}$, BCK Choi $^{2-4 *}$
}

\begin{abstract}
Effective communication of scientific research is critical to advancing science and optimizing the impact of one's professional work. This article provides a guide on preparing scientific manuscripts for publication in the health sciences. It is geared to health professionals who are starting to report their findings in peer-reviewed journals or who would like to refresh their knowledge in this area. It identifies five key steps. First, adopt best practices in scientific publications, including collaborative writing and ethical reporting. Second, strategically position your manuscript before you start to write. This is done by identifying your target audience, choosing three to five journals that reach your target audience and then learning about the journal requirements. Third, create the first draft of your manuscript by developing a logical, concise and compelling storyline based on the journal requirements and the established structure for scientific manuscripts. Fourth, refine the manuscript by coordinating the input from your co-authors and applying good composition and clear writing principles. The final version of the manuscript needs to meet editorial requirements and be approved by all authors prior to submission. Fifth, once submitted, be prepared for revision. Rejection is common; if you receive feedback, consider revising the paper before submitting it to another journal. If the journal is interested, address all the requested revisions. Scientific articles that have high impact are not only good science; they are also highly readable and the result of a collective and often synergistic effort.
\end{abstract}

\author{
Affiliations \\ ${ }^{1}$ Infectious Disease Prevention \\ and Control Branch, Public Health \\ Agency of Canada, Ottawa, ON \\ 2 School of Epidemiology and \\ Public Health, University of \\ Ottawa, Ottawa, ON \\ ${ }^{3}$ Health Promotion and Chronic \\ Disease Prevention Branch, \\ Public Health Agency of Canada, \\ Ottawa, ON \\ ${ }^{4}$ Injury Prevention Research \\ Center, Shantou University \\ Medical College, Shantou, China
}

*Correspondence: bernard.choi@ phac-aspc.gc.ca

Suggested Citation: Huston P, Choi BCK. A guide to publishing scientific research in the health sciences. Can Commun Dis Rep. 2017;43(9):169-75. https://doi.org/10.14745/ccdr.v43i09a01

\section{Introduction}

The publication of the findings of scientific research is important for two reasons. First, the progression of science depends on the publication of research findings in the peer-reviewed literature. Second, the publication of research is important for career development. The old dictum "publish or perish" suggests the critical role publishing research has, especially for those in academia. The newer version, "publish and flourish", suggests that publishing solid scientific research is good for individual researchers and good for the scientific community. With good research, there is the potential for everyone to be better off.

The publication of scientific work is not easy. There are many books on how to write a scientific article (1-5); however, the level of detail may be overwhelming and there is a tendency to focus more on the technical aspects, such as the structure of a scientific manuscript and what to include in each section, and less on the process aspects, such as what constitutes authorship and how to choose the most appropriate journal. There is a need for a basic overview for those who would like to start publishing or refresh their knowledge in this area. The objective of this article is to provide health professionals with an overview on how to prepare manuscripts for publication.

\section{Adopt best practices in scientific publications}

Anyone who would like to author scientific publications should know about these two best practices before they begin: work collaboratively and observe ethical reporting practices.

\section{Practice collaborative writing}

Research and scientific publishing are collective enterprises that call for collaboration as a best practice. Research usually involves a research team. New research projects build on previous research done by others. It involves input from peers on both protocol development before the research is done, as well as the review of manuscripts once the research is completed. The Cochrane Collaboration is one important example of this (6). To optimize the success of your research team, cultivate strong interpersonal skills and choose your collaborators wisely. Areas to consider when you are choosing with whom to work include such things as collaborator availability, similar research interests, track record and personal suitability.

Given that a scientific publication is meant to contribute to knowledge, a good research question is essential, as is identifying the optimal scientific method to answer that question and observing ethical practices in the conduct of your research. 
Once these items have been addressed, what do you need to know before you start to write?

\section{Observe ethical reporting practices}

The ethics of scientific publications can be summarized by two best practices: complete and accurate reporting and appropriate attribution of everyone's contributions (7).

\section{Ensure complete and accurate reporting}

Unethical scientific publication practices include incomplete reporting, the reporting of fraudulent data, plagiarism, duplicate publication and overlapping publications. Some people consider failure to publish the results of clinical trials as unethical (8), as it can create bias in the published record. Incomplete reporting can include selective reporting of findings or not reporting at all. It is important to report negative data, or any unexpected finding.

Falsification or fabrication of data is the most obvious breach of research ethics. One example is the fraudulent study linking autism to vaccine (9), which caused untold harm by undermining public confidence in routine childhood vaccines.

Plagiarism must be carefully avoided. Incorporating others' ideas or research results into any manuscript you write needs to be done with appropriate referencing. Journal editors routinely check manuscripts with antiplagiarism software before determining a manuscript's appropriateness for peer review. Free software programs are available for authors to check for inadvertent duplication of content such as CopyScape, DupliChecker, Plagiarisma, Plagium, Search Engine Reports, SEOTools, Site Liner and Unplag.

Duplicate publication is publishing an article that is the same or overlaps substantially with another article by the author or publisher (8). It is considered redundant, and may result in double-counting of data. This is to be distinguished from co-publication, which is when the same article is published in more than one journal at approximately the same time to increase reach to different disciplines (8). It meets specific criteria and is done with complete transparency.

Overlapping publication is a variant of duplicate publication. It typically occurs with multi-centre trials and is characterized by publications from single centres, several centres as well as all centres. This is considered unethical as it can lead to double-counting and distorts the perception of the weight of the evidence (10). It may be appropriate to have more than one publication come from a multi-centre trial, but this is usually to address secondary outcomes. Secondary publications should cite the primary analysis and all publications of trials should identify the trial registration number (8).

\section{Give appropriate attribution}

It is important to acknowledge the work of everyone who contributed to a scientific publication. Central to ethical publication is appropriate authorship. A best practice is to identify the role of each author. Authorship has been defined by the International Committee of Medical Journal Editors (ICMJE) as those who meet all of the following four criteria: substantial contributions to the conception or design of the work or to the acquisition, analysis or interpretation of data for the work; drafting the initial manuscript or revising it critically for important intellectual content; final approval of the version to be published; and agreement to be accountable for all aspects of the work in ensuring that questions related to the accuracy or integrity of any part of the work are appropriately investigated and resolved (11).

Of note, the collection of data or the development of software for a study are not criteria for authorship, nor is securing research funding; however, these are important contributions that should be acknowledged-either in the Acknowledgements section or, if there is one, in the Contributors section. It is best practice to ensure everyone mentioned in an Acknowledgements or Contributors section is aware he/she has been identified, and is in agreement with being identified. Contractors paid to perform parts of a study (e.g., laboratory testing, software development or drafting the manuscript) are often, by definition, not authors but still merit being identified in the Acknowledgements or Contributors section.

Some unethical practices in authorship include guest authorship and ghost authorship. Guest authorship is including someone as an author who does not meet the ICMJE criteria and ghost authorship is excluding someone as an author who does meet the ICMJE criteria. Basically, ethical attribution is all about transparency.

There can be a lot of debate on the sequencing of authors. The ordering of authors differs by discipline (12). In the health sciences, the first author has the most weight; the final author also carries weight as this is often the principal or most senior investigator. In contrast, in economics, authors are usually listed alphabetically, implying equal contribution to the research work. It is useful to discuss authorship early in the manuscript planning process, and then again near the completion of the manuscript. This discussion should include an assessment of authorship against the ICMJE criteria and consideration of authorship sequence, which may change over time if there were changes in the level of input from what was originally planned.

\section{Position your manuscript}

Once your research is completed, you need to identify appropriate journals for publication. Not every manuscript can or should be published in a prestigious, high-impact journal. People can waste a lot of time and effort sending manuscripts to journals that will promptly send back a polite rejection letter, or will keep it for several months before declining it, based on the peer review. So how do you choose which journal to submit to? Discuss with your co-researchers or peers: Who is the target audience? Who will want to know about this research? What is the best journal to reach that audience? And what are those journals' specific requirements for manuscript submissions?

\section{Identify your target audience}

Before writing up results of your study, think about your potential readers. Are your research findings most appropriate for a general readership or a specialty group? This affects the choice of journal for submission, and the writing style you adopt for the manuscript. 


\section{Choose three to five journals}

Based on your target readership, develop a list of three to five journals, and then order by journal impact factor. The impact factor is the average number of citations per article published in that journal, based on the performance in the previous two years (13). Submit your manuscript to one journal at a time, starting from the top of the list. If you receive a rejection letter from your "Plan A" journal, you have a ready "Plan B" journal to submit to right away. This avoids having the rejected manuscript languish on your desk.

\section{Learn about the journal requirements}

Every journal has instructions for authors that are listed online. These instructions describe the types of articles that the journal publishes and provides specific advice about format, word length, as well as what needs to be included in a cover letter at the time of submission. Consult some past issues of the targeted journals to see examples of the different types of articles that are published.

\section{Create the first draft}

Now that you have identified your target audience, what journal you are targeting first, and what its requirements are, you are ready to create the first draft. To begin you want to develop a high-level summary that establishes a logical, compelling storyline that follows the established structure for a scientific manuscript. Then, before you start to write the text, check for any reporting guides for the type of study you have done to ensure you address any specific reporting requirements.

There is a common misconception that scientific publications are simply dispassionate reports of the methods and results of research. But consider this: There are more than 30,000 biomedical journals (14). We are living in an age of information overload, so people become very selective in what they read and ask themselves "Is this important for me to read?" The objective reporting of research findings is necessary, but not sufficient. Effective authors will also provide an appropriate context and present their work in such a way that readers find it interesting and easy to understand. The sections that follow identify several ways to best present the context, data and implications of your work.

\section{Develop a compelling storyline}

The use of the term storyline here does not mean you endeavour to entertain the reader. It is how you "present your case" in the court of scientific opinion. It maps on to the basic structure of scientific articles and includes the rationale for the study, the research question, how that question was addressed, what was found and why these findings are important (3). After working for months (and sometimes years) on a research project, it is easy to get lost in the details. Establishing a clear, logical underlying structure to your scientific manuscript from the outset not only helps to avoid going off on tangents, it also vastly increases its readability. The abstract is an excellent place to set out the storyline of your manuscript. You want to respond to the questions: What is this research about? (background and objective); What did you do to answer your research question? (methods); What did you find? (results); and What are the implications and next steps? (discussion and conclusion). Then, much like establishing the theme, each section is developed in the manuscript. A well-written abstract gives readers a "road map"; after reading it they will know what you will be covering in the article.

One way to strengthen the logic of your manuscript is to use the same terms and the same sequencing of information in each section. For example, if your research objective was to assess acceptability and adherence to a treatment regimen, what you do not want to do is describe the willingness to start a treatment in the Introduction, note how you measured compliance and adherence in the Methods and then describe how many people followed the treatment regime after agreeing to start it in the Results. If your research objective is to assess acceptability and adherence, define acceptability and then adherence in the Introduction, identify how you measured acceptance and then adherence in the Methods, and describe your findings for acceptance and then adherence in the Results. When you use the same terms in the same sequence in the Introduction, Methods and Results sections, it is much easier for the reader to quickly grasp what you did and what was found.

In addition, there are several writing techniques that help make your manuscript more compelling to engage the reader. The first is to have "a hook", or interesting start that draws the reader in. Titles can be a hook; for example, a recent article from the New England Journal of Medicine was entitled: "The Other Victims of the Opioid Epidemic" (15). It might catch your attention, as you immediately ask yourself "Who are the victims and who are the other victims?" A compelling title may pose a question that motivates people to read the article: "Can scientists and policymakers work together?" (16). Readers are also engaged by the first sentence of the abstract; for example: "The emergence and prevalence of antibiotic-resistant bacteria are an increasing cause of death worldwide, resulting in a global call to action." (17). This is a good first sentence as it gives a sense of urgency and makes the reader curious about what the call to action is. One must be careful to not sensationalize, but when there is an urgent health issue, it is important to describe why we need to be aware of it and change what we do if necessary.

\section{Check for reporting guides}

As a final step before starting to write the manuscript in full, check if there are specific reporting requirements for the type of research you have done; for example, if you have done an experimental study, you will need to mention research ethics board approval and informed consent (18). If you have done a systematic review, include a flow diagram of the included and excluded studies (19). Some journals provide author checklists to identify what is important to include in different sections for different types of studies $(20,21)$. The Equator Network (Enhancing the Quality and Transparency of Health Research) brings together a number of reporting guidelines and is a useful resource (22). 


\section{Use the IMRAD approach}

When you start to write the text, use the classic structure of a scientific article: Introduction, Methods, Results and Discussion, which is often referred to by the acronym IMRAD. But, rather than writing down everything you know that relates to your study, use each section strategically to tell the story of your research.

A good Introduction section has the structure of an inverted triangle. This means that you start with a broad topic, and then narrow down the readers' focus in logical steps until you arrive at your research question. This can be facilitated by answering the following questions:

- What is the issue?

- Why is it important?

- What do we know to date?

- What are the gaps in our knowledge?

- What is the research question that will address this gap?

- What was the objective of the research?

At this point, the reader will want to know "So what happened?" and they will keep reading. The summary of the literature is done in the present tense, as it represents generally accepted facts and principles. Define all abbreviations on first use but use only commonly-accepted ones. Too many abbreviations decrease readability. The introduction is described in the present tense (as it describes established facts).

The Methods section describes how the study was conducted. It is important to explain how the methods address the research objective. Give enough detail so that others can duplicate your study, if needed, to confirm that your results are consistent and reliable. It is useful to have subtitles. For a clinical trial, for example, this could include study population, intervention, outcome measures and analysis. Avoid the temptation to provide results in the Methods section. For example, the sampling methodology belongs to the Methods section, the response rate of the study belongs in the Results section. The Methods section is described in the past tense (as it describes what you did).

The Results section describes what was found in the study (in the same sequence of information established in the Introduction and the Methods sections). Avoid the temptation to discuss or analyze results in the Results section. For example, you can state: "there were more men than women in this study", but exploring the reason for this belongs in the Discussion section. Results are described in the past tense (as they describe what you found).

Many readers find the Discussion section to be the most interesting part of the article. The first sentence is an opportunity to summarize the most important findings of your study; for example: "Surveillance data from four Nordic countries suggested that at least $25 \%$ of gonorrhea infections were related to travel" (23). Interpret your findings in light of possible biases or sources of errors. Then it is important to consider both the strengths and weaknesses of your study; compare it to other studies with similar or different findings, consider the implications and identify the next steps. The Discussion section is an opportunity to situate your findings within the larger body of knowledge and to consider what is needed to further advance scientific understanding. The discussion is described in past, present or future tense depending on context.

\section{Develop tables and figures to highlight key findings}

There are two best practices to consider when creating tables and figures. First, to address the classic evidence-based medicine question-Are these results applicable to my patient population?-you need to describe your study population (24). The first table in a clinical study, for example, often compares the demographic characteristics of the research subjects to what is known about the study population. This helps readers assess how representative the study sample was. Second, use tables and figures to highlight your key findings. Resist the temptation to present all the data you have in tables and figures which may overwhelm the reader. You want to keep the focus on the study objective and the answer to your research question.

Tables are useful to present large quantities of data and figures are preferred to show trends over time. Titles of tables and figures should be able to "stand alone"; i.e., they are self-explanatory and complete. To be complete, include the study population, type of data presented and dates of the study. In tables, ensure each column has a heading. Make sure all data is validated and that all research subjects are accounted for (i.e., the percentages add up to $100 \%$ ). Further resources on preparation of tables and figures are available $(25,26)$. See Table 1 for some highlights of the "Dos and Don'ts" when writing scientific manuscripts.

\section{Table 1: Highlights of common dos and don'ts when writing scientific manuscripts}

\begin{tabular}{|c|c|c|}
\hline Item & Dos & Don'ts \\
\hline Title & $\begin{array}{l}\text { Use accurate, } \\
\text { interesting, and } \\
\text { catchy titles. Example: } \\
\text { "Can scientists and } \\
\text { policymakers work } \\
\text { together?" }\end{array}$ & $\begin{array}{l}\text { Do not use titles that } \\
\text { are too long, such } \\
\text { as: "A multi-sectoral } \\
\text { mixed model study } \\
\text { to examine the } \\
\text { facilitators and barriers } \\
\text { in the collaboration } \\
\text { of scientists and } \\
\text { policymakers in joint } \\
\text { efforts using qualitative } \\
\text { and quantitative } \\
\text { methods". }\end{array}$ \\
\hline Abstract & $\begin{array}{l}\text { Use the abstract to } \\
\text { attract readers and } \\
\text { summarize your story } \\
\text { line. }\end{array}$ & $\begin{array}{l}\text { Do not include content } \\
\text { that is not found in the } \\
\text { article. }\end{array}$ \\
\hline \multicolumn{3}{|c|}{ Introduction (Why?) } \\
\hline Objectives & $\begin{array}{l}\text { Carefully state your } \\
\text { objective, as everything } \\
\text { should follow logically } \\
\text { from the objective. }\end{array}$ & $\begin{array}{l}\text { Do not leave out the } \\
\text { objective or just tie it } \\
\text { in loosely to the rest of } \\
\text { the article. }\end{array}$ \\
\hline \multicolumn{3}{|l|}{ Methods (How?) } \\
\hline Appropriateness & $\begin{array}{l}\text { Ensure and explain how } \\
\text { the research method } \\
\text { addresses the research } \\
\text { objectives. Describe the } \\
\text { methods in sufficient } \\
\text { detail so other people } \\
\text { can repeat the study. }\end{array}$ & $\begin{array}{l}\text { Do not use a cross- } \\
\text { sectional study to } \\
\text { examine causal } \\
\text { associations because } \\
\text { it cannot. Do not } \\
\text { state: "our study used } \\
\text { conventional methods" } \\
\text { without giving a } \\
\text { reference. }\end{array}$ \\
\hline
\end{tabular}


Table 1: Highlights of common dos and don'ts when writing scientific manuscripts (continued)

\begin{tabular}{|c|c|c|}
\hline Item & Dos & Don'ts \\
\hline \multicolumn{3}{|l|}{ Results (What?) } \\
\hline Sequencing & $\begin{array}{l}\text { Order the sequence } \\
\text { of information so that } \\
\text { the Results section } \\
\text { addresses the objective } \\
\text { in a logical way. }\end{array}$ & $\begin{array}{l}\text { Do not present results } \\
\text { in a random fashion or } \\
\text { include results that are } \\
\text { irrelevant. }\end{array}$ \\
\hline Other information & $\begin{array}{l}\text { Include only results of } \\
\text { your study in the Results } \\
\text { section. }\end{array}$ & $\begin{array}{l}\text { The results of other } \\
\text { studies belong either } \\
\text { in the introduction (to } \\
\text { provide context) or the } \\
\text { discussion (to compare } \\
\text { with your results). }\end{array}$ \\
\hline $\begin{array}{l}\text { Use of tables and } \\
\text { figures }\end{array}$ & $\begin{array}{l}\text { Tables and figures } \\
\text { should highlight key } \\
\text { study findings. Text } \\
\text { in the Results section } \\
\text { should complement } \\
\text { tables and figures; for } \\
\text { example, if a table } \\
\text { shows "relative risk=8.5, } \\
P=0.02 ", \text { the text } \\
\text { might read "a strong, } \\
\text { statistically significant } \\
\text { association was found." }\end{array}$ & $\begin{array}{l}\text { Do not simply repeat } \\
\text { data from tables and } \\
\text { figures in the text of } \\
\text { the Results section; } \\
\text { for example, "the } \\
\text { relative risk was } 8.5 \\
\text { and the P-value was } \\
0.02 \text { " is repetitive } \\
\text { of the information } \\
\text { already provided in the } \\
\text { table, and provides no } \\
\text { additional information } \\
\text { for the readers. }\end{array}$ \\
\hline \multicolumn{3}{|c|}{ Discussion and conclusion (So What?) } \\
\hline Main findings & $\begin{array}{l}\text { The first sentence of } \\
\text { the Discussion section } \\
\text { should address your } \\
\text { research objective } \\
\text { and highlight the key } \\
\text { findings of your study. }\end{array}$ & $\begin{array}{l}\text { Do not simply } \\
\text { summarize the results } \\
\text { a second time without } \\
\text { interpretation. }\end{array}$ \\
\hline $\begin{array}{l}\text { Unexpected } \\
\text { results }\end{array}$ & $\begin{array}{l}\text { If results contradict } \\
\text { expectation, look for } \\
\text { possible sources of } \\
\text { bias, such as selection } \\
\text { of subjects, methods } \\
\text { of data collection and } \\
\text { confounding factors. }\end{array}$ & $\begin{array}{l}\text { Do not delete results } \\
\text { simply because they } \\
\text { contradict expectation. } \\
\text { These may be the most } \\
\text { important results of } \\
\text { your study. }\end{array}$ \\
\hline $\begin{array}{l}\text { Contribution to } \\
\text { knowledge }\end{array}$ & $\begin{array}{l}\text { Describe the new } \\
\text { knowledge provided by } \\
\text { this study. }\end{array}$ & $\begin{array}{l}\text { Do not just say "our } \\
\text { study confirmed the } \\
\text { results of previous } \\
\text { studies". }\end{array}$ \\
\hline $\begin{array}{l}\text { Strengths and } \\
\text { limitations }\end{array}$ & $\begin{array}{l}\text { Discuss strengths and } \\
\text { limitations of the study } \\
\text { in a few paragraphs. }\end{array}$ & $\begin{array}{l}\text { Do not overstate the } \\
\text { limitations but do not } \\
\text { hide them either. }\end{array}$ \\
\hline Implications & $\begin{array}{l}\text { Describe how the study } \\
\text { may inform current } \\
\text { practice. Suggest future } \\
\text { research directions. }\end{array}$ & $\begin{array}{l}\text { Do not just say "our } \\
\text { study has made } \\
\text { important contributions } \\
\text { to science". Do not just } \\
\text { say "this study indicates } \\
\text { that future studies are } \\
\text { needed". }\end{array}$ \\
\hline
\end{tabular}

\section{Refine the manuscript}

Most manuscripts are a team effort, so once a manuscript has been drafted, it then needs to be circulated for input by all the co-authors. Consider your own internal peer review process and then refine the manuscript for clarity before submitting it to a peer-reviewed journal. If your first language is not English, consider having the manuscript copy-edited before you submit it to a journal.

\section{Circulate to co-authors and peers}

Each research team works out their own way of writing and revising. Usually the first author develops the first draft, and then sends to other authors to provide comments (usually using the tracked changes function). The first author will then incorporate comments and produce a second draft for a second round of comments. This process continues until all authors agree on the structure and wording of the manuscript. It is also possible to have different authors draft different sections of the manuscript, once there has been consensus on the storyline and the structure. A common challenge with circulating drafts of a manuscript is version control. You may want to have only one author working on a draft at a time. If there is simultaneous feedback from multiple authors, they should all be sent to the first author by a set due date. You may also want to conduct your own internal peer review process. After being steeped in a project for months and a manuscript for weeks, it is easy to lose perspective. An unblinded internal peer review may help strengthen your manuscript before undergoing the blind external peer review that is conducted by the editorial office of scientific journals.

\section{Apply clear writing principles}

The hallmark of good scientific writing is precision and clarity (5). Based on the classic, The Elements of Style, here are some tips that will help bring clarity to your writing (27). Check the first sentence of each paragraph. These should signal to the reader the progression of the logic of your manuscript and introduce what the paragraph contains. When appropriate, use the active voice. To say "We developed a protocol" is more engaging than the passive voice: "A protocol was developed". Edit out needless words, such as "as noted above". When possible, use parallel construction or the repetition of a grammatical form within a sentence. For example, the phrase "Children aged 4-6 years should be given vaccine $A$; the administration of vaccine $B$ is advised for those who are 13-18 years old" can be made clearer using parallel construction: "Children aged 4-6 years should be given vaccine $A$; adolescents aged 13-18 should be given vaccine B". Make definitive assertions; arouse interest of the reader by reporting the details that matter. In addition, you do not want to be overly complex; resources are available to help describe things in plain language (28).

\section{Submit and be ready to revise}

Once all the authors sign off on the final version, submit to your journal of choice with a short cover letter noting that your manuscript has not been published previously and is not under consideration by any other journal. It is also useful to identify why your manuscript is relevant to the journal's readership. This may influence the editor's decision on whether to send your manuscript for external peer review.

Once the manuscript is submitted, brace yourself for a number of possible responses. You may receive a polite rejection letter. 
Or the Editor may have comments on the manuscript that need to be addressed before it is peer-reviewed. If this is the case, it is good to address these promptly. Another possibility is that the manuscript is peer-reviewed and then declined. There are two reasons why you should carefully consider all the peer-reviewer comments, even though the journal is not interested in your manuscript. First, this is free advice, often from top-notch experts in the field, so why not use it to improve your success rate with another journal? Second, only a limited number of researchers participate in the journal peer review process. When you submit to a second journal, what you do not want to hear back is "I was the peer reviewer of this manuscript for another journal, and I see that none of my previous comments were considered by the authors". If you do decide to revise the manuscript to address reviewer comments, do not forget to review the instructions for authors for the new journal and reformat as necessary. Finally, after peer-review has been completed, you may receive a tentative acceptance letter from the editor, accompanied by a request for minor revisions. Or you could receive a "reject and resubmit" letter, which means that extensive revisions are needed. In either case, it indicates an interest in a revised manuscript.

Requested revisions are usually discussed jointly among the co-authors until there is consensus on how to address them. Making the revisions can either be allocated among the authors, or coordinated through one person. Usually once the revisions are underway, they do not seem as formidable as they first appeared, and the manuscript ends up being stronger and clearer as a result. Once revised, do a final check of the abstract to ensure it still reflects the revised text. Again, sign-off is needed from all the authors before submitting the revised manuscript to the journal.

\section{Discussion}

To advance science, research needs to be published. To optimize the chances of your research getting published and having an impact, it is important to demonstrate objectivity, and present your work in a way that is interesting and compelling. To do this you need clarity, logic and the use of rhetorical techniques to engage the reader in your research. This includes positioning your manuscript to reach your target audience, developing a logical, compelling storyline within the confines of the IMRAD structure, having an effective iterative approach among your co-authors to develop the manuscript and being ready to complete revisions to meet journal requirements.

Effective scientific writing rarely comes from innate talent. Writing is a skill that needs to be honed over one's professional career. Cultivate an interest in what makes good writing. As you read other peoples' work, ask yourself what makes some articles easier to read than others. Consider becoming a peer-reviewer for scientific journals to assess the manuscripts of others.

\section{Conclusion}

It is thoroughly satisfying to publish compelling research that influences people and makes a contribution to science. This is most often achieved through the synergy of collaboration with others and having a common goal of advancing the collective progression of science.

\section{Conflict of Interest}

None.

\section{Authors' statement}

Both authors worked on the conception and design together, $\mathrm{PH}$ developed the first draft, both contributed to multiple drafts and signed off on the final version. Dr. Patricia Huston is the Editor-inChief of CCDR and recused herself from taking any editorial decisions on this manuscript. Decisions were taken by the Editorial Fellow, Toju Ogunremi, with the support of the Editorial Board member, Dr. Michel Deilgat.

\section{Acknowledgements}

Our thanks to Andrea Currie and Katie Rutledge-Taylor who developed the Public Health Agency of Canada's Field Epidemiology writing curriculum. We had a number of interesting discussions on the art and science of scientific writing that informed this work, including the concept of the inverted triangle for the structure of an effective introduction.

\section{References}

1. Gastel B, Day RA. How to Write and Publish a Scientific Paper, 8th edition. Santa Barbara, USA: Greenwood, 2016.

2. Cargill M, O'Connor P. Writing Scientific Research Articles: Strategy and Steps. West Sussex, UK: John Wiley-Blackwell, 2013.

3. Schimel J. Writing Science: How to Write Papers that get Cited and Proposals that get Funded. New York, USA: Oxford University Press USA, 2012.

4. Albert T. Winning the Publications Game: The Smart Way to Write your Paper and get it Published, 4th edition. New York USA, CRC Press Taylor\&Francis Group, 2016.

5. Katz MJ. From Research to Manuscript: A Guide to Scientific Writing. Springer Science \& Business Media; 2009.

6. The Cochrane Collaboration. About us. http://www. cochrane.org/about-us [Accessed July 20, 2017].

7. Hammes GG. The ACS style guide: Effective Communication of Scientific Information. American Chemical Society; 2006. Chapter 1: Ethics in Scientific Publication in: Coghill AM, Garson LR, editors.

8. International Committee of Medical Journal Editors (ICMJE). Recommendations for the conduct, reporting, editing, and publication of scholarly work in medical journals. Updated 2016. http://www.icmje.org/icmje-recommendations.pdf

9. Godlee F, Smith J, Marcovitch H. Wakefield's article linking MMR vaccine and autism was fraudulent. BMJ. 2011;342:c7452. DOI (http://dx.doi.org/10.1136/ bmj.c7452). PubMed (https://www.ncbi.nlm.nih.gov/ entrez/query.fcgi?cmd=Retrieve\&db=PubMed\&list_ uids $=21209060 \&$ dopt $=$ Abstract).

10. Huston $P$, Moher D. Redundancy, disaggregation, and the integrity of medical research. Lancet. $1996 \mathrm{Apr}$ 
13;347(9007):1024-6. DOI (http://dx.doi.org/10.1016/ S0140-6736(96)90153-1). PubMed (https://www.ncbi.nlm. nih.gov/entrez/query.fcgi?cmd=Retrieve \&db=PubMed\&li st_uids $=8606568 \&$ dopt $=$ Abstract).

11. International Committee of Medical Journal Editors (ICMJE), 2017. Defining the role of authors and contributors. http:// www.icmje.org/recommendations/browse/roles-andresponsibilities/defining-the-role-of-authors-and-contributors. html

12. Choi BCK, Pak AWP. Multidisciplinarity, interdisciplinarity and transdisciplinarity in health research, services, education and policy: 2. Promotors, barriers, and strategies of enhancement. Clinical and Investigative Medicine 2007;30:E224-E232. DOI (http://dx.doi.org/10.25011/ cim.v30i6.2950). PubMed (https://www.ncbi.nlm.nih. gov/entrez/query.fcgi?cmd=Retrieve\&db=PubMed\&lis t_uids $=18053389 \& d o p t=A b s t r a c t)$.

13. Garfield E. The history and meaning of the journal impact factor. JAMA. 2006;295(1):90-3. DOI (http://dx.doi. org/10.1001/jama.295.1.90). PubMed (https://www.ncbi.nlm. nih.gov/entrez/query.fcgi?cmd=Retrieve\&db=PubMed\&li st_uids=16391221\&dopt=Abstract).

14. Klassen TP, Jadad AR, Moher D. Guides for reading and interpreting systematic reviews. 1. Getting started. Arch Pediatr Adolesc Med. 1998;152:700-4. DOI (http://dx.doi. org/10.1001/archpedi.152.7.700). PubMed (https://www. ncbi.nlm.nih.gov/entrez/query.fcgi?cmd=Retrieve\&db=PubM ed\&list_uids=9667544\&dopt=Abstract).

15. Glod SA. The Other Victims of the Opioid Epidemic. N Engl J Med. 2017; 376:2101-2102. DOI (http://dx.doi. org/10.1056/NEJMp1702188). PubMed (https://www.ncbi. nlm.nih.gov/entrez/query.fcgi?cmd=Retrieve\&db=PubMed\&l ist_uids=28564563\&dopt=Abstract).

16. Choi BCK, Pang T, Lin V, Puska P, Sherman G, Goddard M, Ackland MJ, Sainsbury P, Stachenko S, Morrison H, Clottey C. Can scientists and policymakers work together? Journal of Epidemiology and Community Health. 2005;59:632-637. DOI (http://dx.doi.org/10.1136/jech.2004.031765). PubMed (https://www.ncbi.nlm.nih.gov/entrez/query.fcgi?cmd=Retrie ve\&db=PubMed\&list_uids=16020638\&dopt=Abstract).

17. Ersoy SC, Heithoff DM, Barnes L 5th, Tripp GK, House JK, Marth JD, Smith JW, Mahan MJ. Correcting a Fundamental Flaw in the Paradigm for Antimicrobial Susceptibility Testing. EBioMedicine. 2017 May 29. 20;173-81. DOI (http://dx.doi. org/10.1016/j.ebiom.2017.05.026). PubMed (https://www. ncbi.nlm.nih.gov/entrez/query.fcgi?cmd=Retrieve\&db=PubM ed\&list_uids=28579300\&dopt=Abstract).
18. Panel on Research Ethics (PRE). Tri-council Policy Statement: Ethical Conduct for Research Involving Humans. Ottawa Canada: Canadian Institutes of Health Research, Natural Sciences and Engineering Research Council of Canada, Social Sciences and Humanities Research Council of Canada; 2014. http://www.pre.ethics.gc.ca/eng/policy-politique/ initiatives/tcps2-eptc2/Default/

19. Moher D, Llberati A, Tetzlaff J, Altman DG, The PRISMA Group. Preferred reporting items for systemic reviews and meta-analyses: The PRISMA Statement. PLoS Med. 209;6(7):e1000097. DOI (http://dx.doi.org/10.1371/ journal.pmed.1000097). PubMed (https://www.ncbi.nlm. nih.gov/entrez/query.fcgi?cmd=Retrieve \&db=PubMed\&li st_uids=19621072\&dopt=Abstract).

20. Outbreak reporting guide. Can Commun Dis Rep. 2015;41(4):73-5. http://www. phac-aspc.gc.ca/publicat/ccdrrmtc/15vol41/dr-rm41-04/surv-2-eng.php

21. Surveillance summary reporting guide. Can Commun Dis Rep. 2015;41(4):76-8. http://www.phac-aspc.gc.ca/publicat/ ccdr-rmtc/15vol41/dr-rm41-04/surv-3-eng.php

22. The Equator Network (Enhancing the Quality and Transparency of Health Research). Oxford: EQUATOR Network; 2015. http://www.equator-network.org/

23. Beauté J, Cowan S, Hiltunen-Back E, Kløvstad H, Velicko I, Spiteri G. Travel-associated gonorrhoea in four Nordic countries, 2008 to 2013. Euro Surveill. 2017;22(20):pii=30537. DOl (http://dx.doi.org/10.2807/15607917.ES.2017.22.20.30537). PubMed (https://www.ncbi.nlm. nih.gov/entrez/query.fcgi?cmd=Retrieve \&db=PubMed\&li st_uids=28537548\&dopt=Abstract).

24. Centre for Evidence-Based Medicine. Critical Appraisal Tools. Nuffield Department of Primary Care Health Sciences. http:// www.cebm.net/critical-appraisal/ [Accessed July 20, 2017].

25. Lang TA, Secic M. How to Report Statistics in Medicine: Annotated Guidelines for Authors, Editors, and Reviewers. 2nd edition. Philadelphia USA; American College of Physicians Press; 2006.

26. Evergreen Stephanie DH. Presenting Data Effectively: Communicating Your Findings for Maximum Impact. 2nd edition. Thousand Oaks USA; Sage Publications; 2017.

27. Strunk W, White EB. Elements of Style. New York USA: Allyn \& Bacon; 2000.

28. Plain Language Action and Information network (PLAIN). Simple Words and Phrases. http://www. plainlanguage.gov/ howto/wordsuggestions/simplewords.cfm [Accessed 2017]. 